\title{
Sistem Cerdas dalam Mengidentifikasi Kematangan Buah Naga Berdasarkan Fitur Tekstur dengan Metode K-Nearest Neighbor
}

\author{
Abd Rahmat Karim Haba ${ }^{\mathrm{a}, 1,{ }^{*}}$ dan Husdi ${ }^{\mathrm{a}, 2}$ \\ ${ }^{a}$ Universitas Ichsan Gorontalo, Jl. Achmad Najamuddin, Kota Gorontalo dan Kode Pos 96115, Indonesia \\ ${ }^{1}$ rkarimhaba@gmail.com; ${ }^{2}$ husdi@gmail.com \\ * corresponding author
}

\begin{abstract}
INFORMASI ARTIKEL
ABSTRAK

Dikirim : : 18 Oktober 2020

Diulas : 06 Desember 2020

Direvisi : 27 Desember 2020

Diterbitkan : 28 Desember 2020

Selama ini petani kebun buah naga dalam melakukan pemilihan buah naga yang telah matang pada musim panen terkadang masih memiliki kendala seperti melalukan penyortiran untuk mengidentifikasi mana yang sudah matang atau belum matang, hal ini dikarenakan pada buah naga terdapat kulit atau teksturnya

Kata Kunci: yang tebal. Salah satu inovasi informasi dan kominikasi dalam bidang pertanian dengan menggunakan cara menerapkan sistem pengidentifikasian menggunakan

Buah Naga

GLCM

K-Nearest Neighbor metode K-Nearest Neighboar pada system cerdas. Tujuan dari penelitian ini adalah untuk melakukan identifikasi kematangan buah naga dengan system cerdas dan untuk memperoleh system cerdas yang efektif dan efisien sehingga dapat di implementasikan. Penelitian ini menggunakan fitur ekstraksi GLCM sebagai metode untuk mendapatkan nilai tekstur pada gambar (citra) serta dalam melakukan pendeteksian menggunakan metode K-Nearest Neighbor. Dari hasil identifikasi dapat diukur dari perhitungan sudut $0^{\circ}, 45^{\circ}, 90^{\circ}$ dan $130^{\circ}$ serta jarak ketetanggan $\mathrm{K}=3$, serta dapat di implementasikan.
\end{abstract}

Keywords:

Dragon Fruit

GLCM

K-Nearest Neighbor

\section{ABSTRACT}

So far, dragon fruit garden farmers in selecting ripe dragon fruit in the harvest season sometimes still have problems such as sorting to identify which ones are ripe or not yet ripe, this is because dragon fruit has skin or a thick texture. One of the innovations in information and communication in agriculture is by applying an identification system using the K-Nearest Neighbor method on an intelligent system. The purpose of this research is to identify the maturity of dragon fruit with an intelligent system and to obtain a smart system that is effective and efficient so that it can be implemented. This study uses the GLCM extraction feature as a method for obtaining texture values in images (images) and in detecting using the K-Nearest Neighbor method. From the identification results can be measured from the calculation of the angle $0^{\circ}, 45^{\circ}, 90^{\circ}$ and $130^{\circ}$ as well as the proximity distance $\mathrm{K}=3$, and can be implemented.

This is an open access article under the CC-BY-SA license.

\section{Pendahuluan}

Buah Naga termasuk Salah satu jenis buah yang disukai oleh masyarakat dan juga mempunyai banyak manfaat bagi Kesehatan [1]. Buah ini berbentuk bulat memanjang serta kulitnya agak tebal [2]. Selama ini petani kebun buah naga dalam melakukan pemilihan buah naga yang telah matang pada musim panen terkadang masih memiliki kendala seperti melakukan penyortiran untuk mengidentifikasi mana yang sudah matang atau belum, hal ini dikarenakan pada buah naga terdapat kulit atau teksturnya yang tebal, sehingga tidak efektif dan efisien dalam mengetahui kematangan buah naga dan terlebih lagi mesti harus dibelah buahnya untuk mengetahui sudah matang buah naga tersebut atau belum. 
Salah satu inovasi informasi dan komunikasi dalam bidang pertanian dengan menggunakan metode KNearest Neighbor dengan teknik pengolahan citra digital pada sistem cerdas. Dalam penelitian ini menggunakan teknik Pengolahan citra digital sebagai pengganti penglihatan manusia [3], Pengolahan citra digital juga biasa disebut dengan teknik mengolah citra [4]. Citra juga memiliki banyak mengandung informasi [5].

Ada beberapa peneliti sebelumnya menggunakan KNN yaitu Johan Wahyudi dengan hasil penerapan metode KNN dan GLCM mampu dalam mempermudah untuk membedakan motif sasirangan dengan kain tradisional lainnya[6]. Nama Danar Putra Pamungkas dengan hasil penelitian identifikasi Orchidaceae atau bunga anggrek mencapai $80 \%$ dengan rata-rata 77\%[7]. Peneliti Sebastian RoriListyanto dengan hasil klasifikasi didapatkan akurasi tertinggi dengan menggunakan sudut $45^{\circ}$, jumlah data training dan testing 150 dan 60 serta jarak 3 piksel[8]. Moh. Arie Hasan dengan menggunakan algoritma Principal Component Analysis dan KNearest Neighbor dapat digunakan dalam proses klasifikasi jenis songket[9]. Penelitian atas nama Feri Agustina, Dalam penelitian ini di peroleh tigkat keakuratan system ini yaitu 85\%[10] Penelitian atas nama Chandra Wijaya, Hasil penelitian menunjukkan bahwa akurasi terbaik per kelas adalah $66,20 \%$ untuk $\mathrm{K}=5$ [11].

Penelitian ini menggunakan fitur ekstraksi yang mana untuk mendapatkan Informasi fitur pada setiap citra dinyatakan sebagai sebuah vektor yang mengandung elemen-elemen fitur[12]. Berbagai macam metode pada fitur ekstraksi penelitian ini menggunakan Gray Level Co-occurrence Matrix (GLCM) dimana pada GLCM ini merupakan deskriptor tekstur yang baik[13]. Selain fitur ekstraksi peneliti juga menggunakan metode KNearest Neighbor, K-Nearest Neighbor (KNN) tergolong algoritma supervised learning yang dimana sebagian besar dari kategori dalam KNN merupakan hasil nilai klasifikasi dari query instance yang baru [14]

\section{Metode}

Penelitian ini terdiri dari beberapa tahapan:

1. Pengumpulan Data

Data yang didapatkan dari hasil penelitian ini berupa image (citra) dari buah naga merah sebanyak 110 buah naga merah.

2. Pembagian Data Gambar

Gambar yang didapatkan akan dipisahkan menjadi 2 bagian yaitu data training dan data testing, yang mana pada data training sebanyak 100 Gambar dan untuk data testing sebanyak 10 gambar.

3. Preprocessing Gambar

Pada tahapan berikutnya peneliti melakukan transformasi warna gambar yang dari warna RGB diubah menjadi gambar keabuan (grayscale).

4. Fitur Ekstraksi

Pada fitur ekstraksi dalam penelitian ini bertujuan untuk mendapatkan nilai ciri tiap pixel pada gambar buah naga merah. Pada penelitian ini menggunakan Contrast, Correlation, Energy, Entropy dan Homogenity[15]. Berikut persamaan dari fitur yang digunakan:

a. Contrast persamaan (1)

$$
\sum i, j|i-j| 2 p(i, j)
$$

b. Correlation persamaan (2)

$$
\sum i, j \frac{(1-\mu i)(j-\mu j) p(i, j)}{\sigma x \sigma y}
$$

c. Energy persamaan (3)

$$
\sum i, j P(i, j) 2
$$

d. Entropy persamaan (4)

$$
-\sum_{i=1}^{l} \sum_{j=1}^{l}(\operatorname{GLCM}(i, j) \cdot \log (\operatorname{GLCM}(i, j))
$$

e. Homogenity persaman (5)

$$
\sum i, j \frac{p(i, j)}{1+|i, j|}
$$


5. Metode K-Nearest Neighbor

Metode klasifikasi yang menentukan kategori berdasarkan mayoritas kategori pada $k$-tetangga terdekat. Selanjutnya kategori data uji D ditentukan berdasarkan label mayoritas kategori dalam himpunan $k$ tetangga terdekat[16]. Penghitungan jarak dapat dicari menggunakan euclidian distance ditunjukan pada persamaan (6).

$D i=\sqrt{\sum_{i=1}^{k}(x i-y i) 2}$

6. Hasil Identifikasi

Setalah citra baru yang di uji akan mendapatkan hasil sesuai kategori. Kategori yang dimaksudkan adalah berupa gambar buah naga yang matang atau yang belum matang.

Adapun alur dari tahapan penelitian ini dapat dilihat pada Gambar 1 yaitu terdiri dari 6 tahapan.

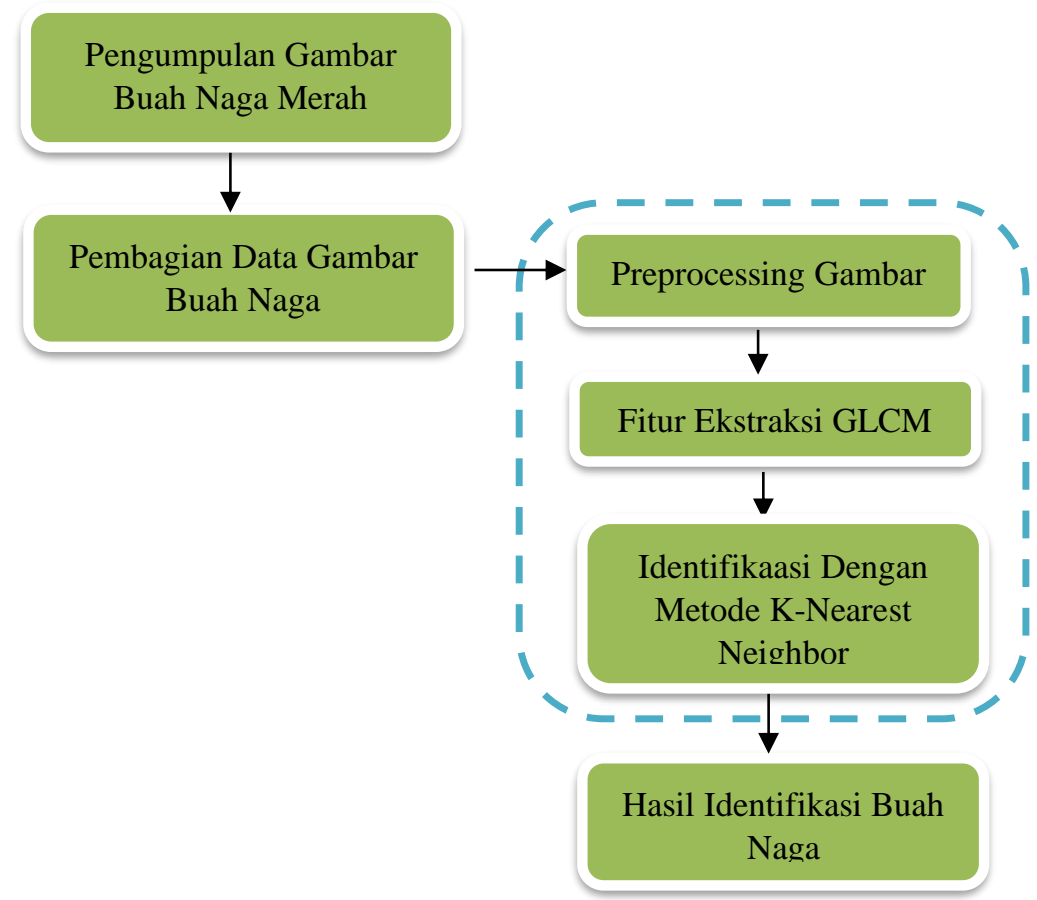

Gambar 1. Tahapan Penelitian

\section{Hasil dan Pembahasan}

\section{A. Pengumpulan Gambar}

Gambar didapatkan dari lokasi penelitian, gambar tersebut berupa buah naga yang matang da naga juga buah yang belum matang.

B. Pembagian Data Gambar
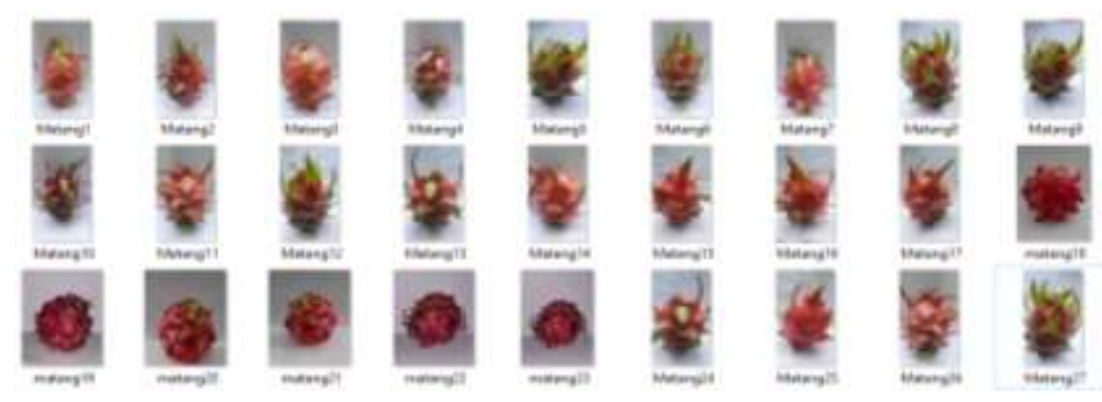

Gambar 2. Buah Naga yang telah matang 
Pada Gambar 2 merupakan gambar buah naga yang telah matang.

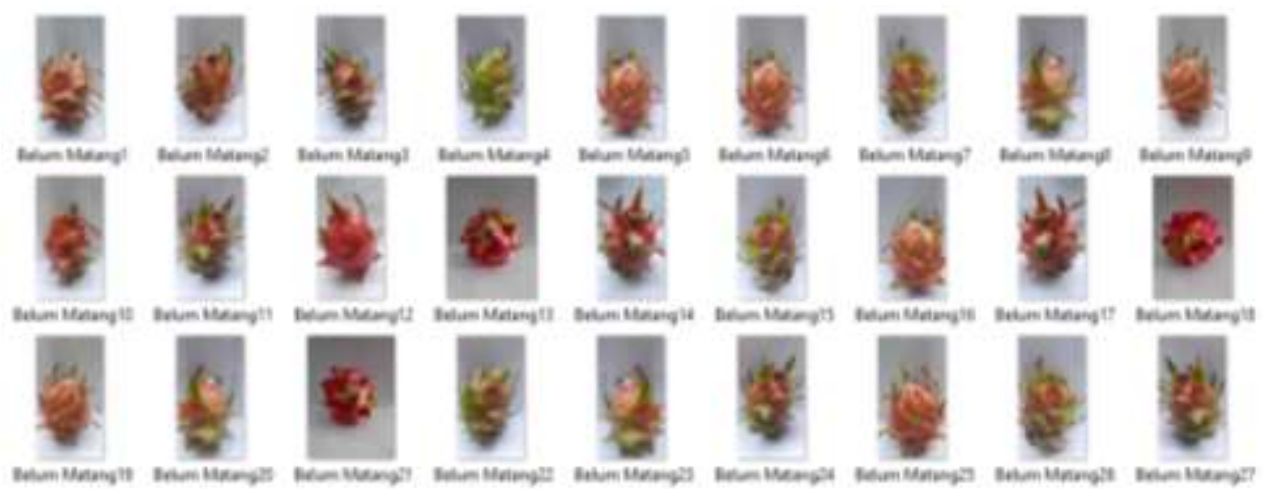

Gambar 3. Buah Naga yang belum matang

Pada Gambar 3 merupakan gambar buah naga yang belum matang.

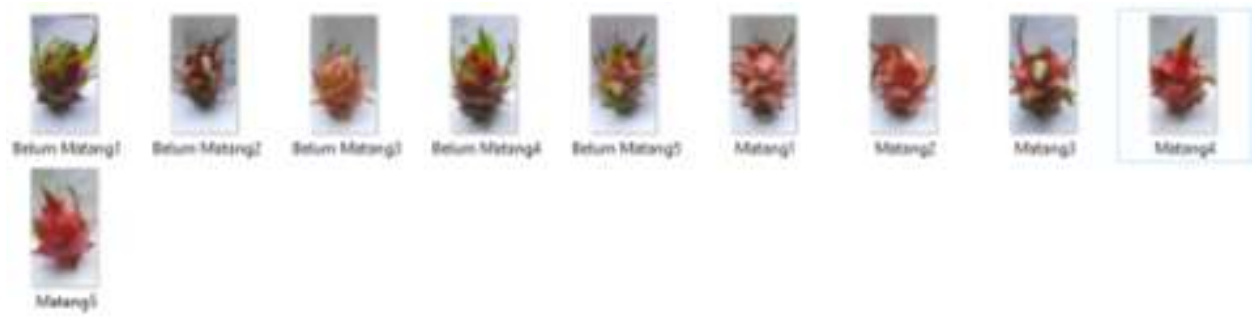

\section{Gambar 4. Data Uji}

Gambar 4 merupakan data uji citra buah naga merah dimana terdapat 5 gambar buah naga merah yang matang dan 5 gambar yang belum matang.

\section{Preprocessing Gambar}

Tahapan ini yang mana gambar awalnya format RGB diolah ke dalam format grayscale, tujuannya supaya mempermudah untuk mengolahnya. Berikut gambar RGB ke grayscale ditampilkan pada Tabel 1.

Tabel 1. Format RGB ke Grayscale

\begin{tabular}{llll}
\hline No & Gambar RGB & Gambar Grayscale & Keterangan \\
\hline 1 & Belum Matang & Belum Matang \\
\hline 3 & & & \\
\hline
\end{tabular}




\begin{tabular}{cccc}
\hline No & Gambar RGB & Gambar Grayscale & Keterangan \\
\hline & & & Belum \\
& & & \\
& & & \\
& & & \\
\hline
\end{tabular}

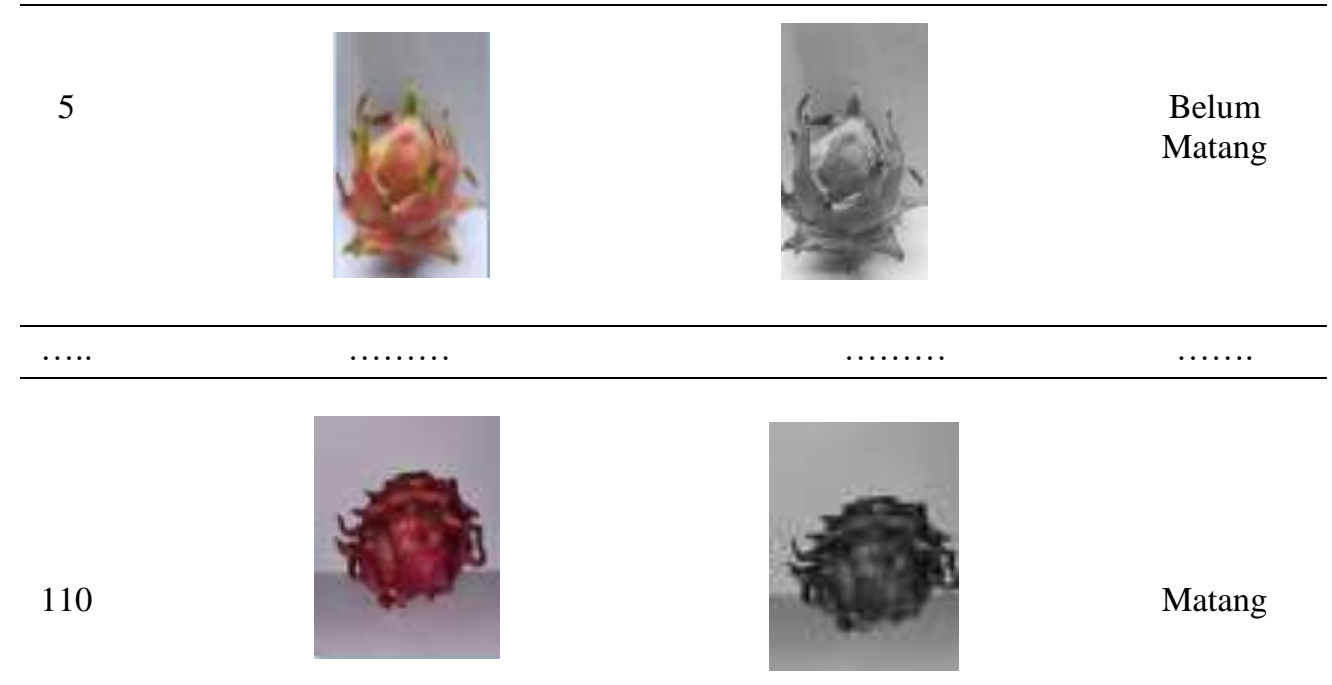

\section{Fitur Ekstraksi}

Fitur yang digunakan adalah GLCM, yang mana meliputi nilai dari Contrast, Energy, Correlation, Entropy dan Homogenity. Berikut Tabel dari nilai fitur ekstraksi disajikan pada Tabel 1.

Tabel 2. Nilai Fitur Ekstraksi $0^{0}$

\begin{tabular}{|c|c|c|c|c|c|c|}
\hline No & Nama Gambar & Contras & Energy & Entropy & Homogenity & Correlation \\
\hline 1 & $\begin{array}{l}\text { Buah Naga Belum } \\
\text { Matang1 }\end{array}$ & 18.09709 & 2.941149 & 0.004951 & 0.995197 & 0.694095 \\
\hline 2 & $\begin{array}{l}\text { Buah Naga Belum } \\
\text { Matang2 }\end{array}$ & 14.36519 & 2.885761 & 0.004417 & 0.997141 & 0.738058 \\
\hline 3 & $\begin{array}{l}\text { Buah Naga Belum } \\
\text { Matang3 }\end{array}$ & 14.07713 & 2.943531 & 0.003938 & 0.997292 & 0.717989 \\
\hline 4 & $\begin{array}{l}\text { Buah Naga Belum } \\
\text { Matang4 }\end{array}$ & 11.22968 & 2.952172 & 0.002924 & 0.99809 & 0.704654 \\
\hline 5 & $\begin{array}{l}\text { Buah Naga Belum } \\
\text { Matang5 }\end{array}$ & 97.08636 & 2.669701 & 0.014602 & 0.971522 & 0.667768 \\
\hline$\ldots$ & $\ldots$ & $\ldots$ & $\ldots \ldots$ & $\ldots \ldots \ldots$ & $\ldots \ldots$ & $\ldots \ldots$ \\
\hline 110 & Buah Naga Matang55 & 139,0794 & 2,665968 & 0,021445 & 0,96927 & 0,653425 \\
\hline
\end{tabular}

Tabel 2 merupakan nilai fitur dengan menggunakan derajat $0^{0}$.

Tabel 3. fitur GLCM $45^{0}$

\begin{tabular}{clccccc}
\hline No & Nama Gambar & Contras & Energy & Entropy & Homogenity & Correlation \\
\hline 1 & $\begin{array}{l}\text { Buah Naga Belum } \\
\text { Matang1 }\end{array}$ & 36,28411 & 3,091022 & 0,00371 & 0.990363 & 0,62258 \\
\hline 2 & $\begin{array}{l}\text { Buah Naga Belum } \\
\text { Matang2 }\end{array}$ & 23,0114 & 3,031325 & 0,003309 & 0,99542 & 0,665923 \\
\hline
\end{tabular}




\begin{tabular}{clccccc}
\hline No & \multicolumn{1}{c}{ Nama Gambar } & Contras & Energy & Entropy & Homogenity & Correlation \\
\hline 3 & $\begin{array}{l}\text { Buah Naga Belum } \\
\text { Matang3 }\end{array}$ & 25,84523 & 3,088504 & 0,003025 & 0,995027 & 0,646551 \\
\hline 4 & $\begin{array}{l}\text { Buah Naga Belum } \\
\text { Matang4 }\end{array}$ & 20,02757 & 3,091163 & 0,002151 & 0,996593 & 0,63102 \\
\hline 5 & $\begin{array}{l}\text { Buah Naga Belum } \\
\text { Matang5 }\end{array}$ & 161,903 & 2,830036 & 0,011456 & 0,952531 & 0,556662 \\
\hline$\ldots$. & $\ldots \ldots$ & $\ldots$. & $\ldots \ldots$ & $\ldots \ldots$ & $\ldots \ldots$ \\
\hline 110 & Buah Naga Matang55 & 274,3638 & 2,8507 & 0,018246 & 0,939547 & 0,510725 \\
\hline
\end{tabular}

Tabel 3 merupakan perhitungan dari derajat $45^{0}$

Tabel 4. Fitur GLCM $90^{\circ}$

\begin{tabular}{clccccc}
\hline No & \multicolumn{1}{c}{ Nama Gambar } & Contras & Energy & Entropy & Homogenity & Correlation \\
\hline 1 & $\begin{array}{l}\text { Buah Naga Belum } \\
\text { Matang1 }\end{array}$ & 23,16256 & 2,983804 & 0,004311 & 0,993849 & 0,676125 \\
\hline 2 & $\begin{array}{l}\text { Buah Naga Belum } \\
\text { Matang2 }\end{array}$ & 15,21932 & 2,93297 & 0,003824 & 0,996973 & 0,716892 \\
\hline 3 & $\begin{array}{l}\text { Buah Naga Belum } \\
\text { Matang3 }\end{array}$ & 14,58559 & 2,961462 & 0,003598 & 0,997195 & 0,710799 \\
\hline 4 & $\begin{array}{l}\text { Buah Naga Belum } \\
\text { Matang4 }\end{array}$ & 15,02341 & 2,969978 & 0,00291 & 0,997445 & 0,702313 \\
\hline 5 & $\begin{array}{l}\text { Buah Naga Belum } \\
\text { Matang5 }\end{array}$ & 78,62562 & 2,732924 & 0,013633 & 0,976851 & 0,614201 \\
\hline$\ldots$ & $\quad \ldots . \ldots$ & $\ldots \ldots$ & $\ldots \ldots$ & $\ldots \ldots$ \\
\hline 110 & Buah Naga Matang55 & 135,1825 & 2,743334 & 0,020357 & 0,970022 & 0,576359 \\
\hline
\end{tabular}

Tabel 4 merupakan Perhitungan dari $90^{\circ}$

Tabel 5. Fitur GLCM $135^{\circ}$

\begin{tabular}{clccccc}
\hline No & Nama Gambar & Contras & Energy & Entropy & Homogenity & Correlation \\
\hline 1 & $\begin{array}{l}\text { Buah Naga Belum } \\
\text { Matang1 }\end{array}$ & 34,01463 & 3,0831 & 0,003718 & 0,990966 & 0,625205 \\
\hline 2 & $\begin{array}{l}\text { Buah Naga Belum } \\
\text { Matang2 }\end{array}$ & 28,59132 & 3,041355 & 0,00327 & 0,99431 & 0,664326 \\
\hline 3 & $\begin{array}{l}\text { Buah Naga Belum } \\
\text { Matang3 }\end{array}$ & 24,50421 & 3,071377 & 0,003069 & 0,9952585 & 0,654986 \\
\hline 4 & $\begin{array}{l}\text { Buah Naga Belum } \\
\text { Matang4 }\end{array}$ & 26,45461 & 3,092926 & 0,002237 & 0,995499 & 0,635316 \\
\hline 5 & $\begin{array}{l}\text { Buah Naga Belum } \\
\text { Matang5 }\end{array}$ & 158,6841 & 2,883863 & 0,01138 & 0,953475 & 0,552973 \\
\hline$\ldots$ & $\quad \ldots . \ldots$ & $\ldots \ldots$ & $\ldots \ldots$ & $\ldots \ldots$ & $\ldots \ldots$ \\
\hline 110 & Buah Naga Matang55 & 218,5835 & 2,835236 & 0,018176 & 0,95184 & 0,516908 \\
\hline
\end{tabular}

Pada Tabel 5 merupakan perhitungan dari GLCM 135

\section{E. Identifikasi Dengan Metode K-Nearest Neighbor}

Nilai yang telah didapatkan dari GLCM akan digunakan di metode K-Nearest Neighbor, dari metode ini nantinya akan didapatkan hasil identifikasi apakah buah yang didapatkan matang atau belum matang, $K-$ Nearest Neighbor sendiri peneliti menggunakan jarak ketetanggan terdekat $\mathrm{K}=3$, dari jarak ini dapat diukur sehingga dapat melakukan identifikasi. 
F. Hasil Identifikasi

21 una

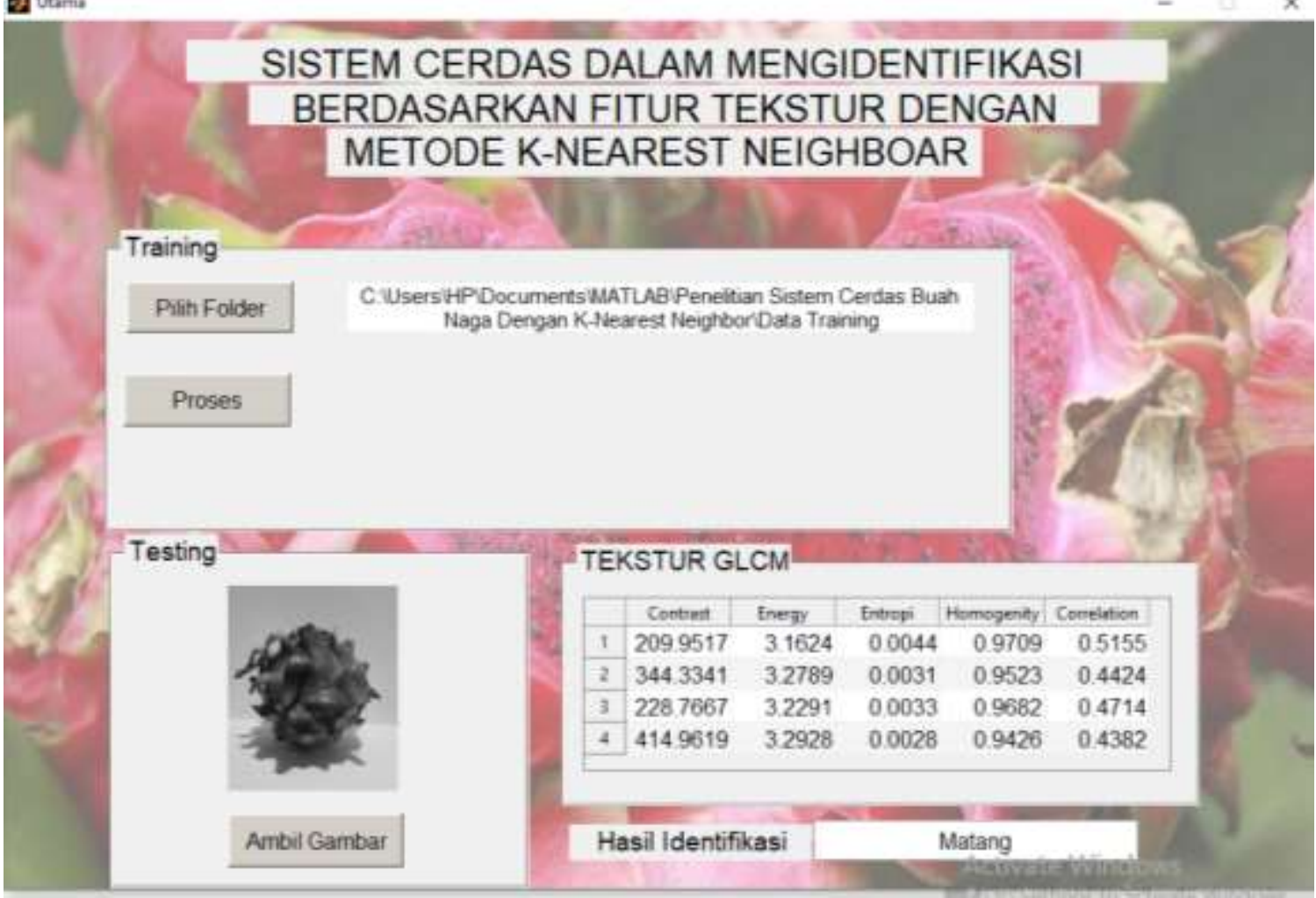

Gambar 5. Hasil Identifikasi

Gambar 5. Merupakan hasil identifikasi data citra uji menggunakan metode K-Nearest Neighbor. Pada metode $K$-Nearest Neighbor, menggunakan cara atau teknik dengan pencarian nilai terdekat berdasarkan ketetanggan. Hasil akhirnya adalah nilai ketetanggaan dari citra data uji dengan ketentuan kategorinya. Kategori yang dimaksud adalah berupa buah naga yang matang dengan buah naga yang belum matang.

\section{Kesimpulan}

Berdasarkan hasil yang telah dilakukan, bahwa dengan sistem cerdas menggunakan metode K-Nearest Neighbor pada citra buah naga dapat di identifikasi dan dapat diimplemantasikan. Dari hasil identifikasi dapat diukur dari perhitungan sudut $0^{\circ}, 45^{\circ}, 90^{\circ}$ dan $130^{\circ}$ serta jarak ketetanggan $\mathrm{K}=3$. Adapun saran dari penelitian ini, yaitu padapeneliti yang ingin mengembangkan sistem cerdas ini diharapkan adanya penambahan fitur ekstraksi selain GLCM sehingga dapat dipadukan nantinya. Serta data gambar yang akan digunakan ditambahkan lebih banyak lagi dari penelitian ini.

\section{Daftar Pustaka}

[1] L. O. Prakoso, H. Yusmaini, M. S. Thadeus, and S. Wiyono, "Perbedaan efek ekstrak buah naga merah (Hylocereus polyrhizus) dan ekstrak buah naga putih (Hylocereus undatus) terhadap kadar kolesterol total tikus putih (Rattus norvegicus)," J. Gizi dan Pangan, vol. 12, no. 3, pp. 195-202, 2017.

[2] N. Khuriyati, "Kualitas Buah Naga Nafis Khuriyati et al Nafis Khuriyati et al Kualitas Buah Naga," vol. 23, no. 2, 2018.

[3] T. Y. Prahudaya and A. Harjoko, "Metode Klasifikasi Mutu Jambu Biji Menggunakan Knn Berdasarkan Fitur Warna Dan Tekstur," J. Teknosains, vol. 6, no. 2, p. 113, 2017.

[4] I. W. Pratama, P. Teknik, I. Fakultas, T. Universitas, and I. Lamongan, "Algoritma knn untuk klasifikasi kematangan buah apel berdasarkan tekstur," vol. 11, pp. 45-48, 2020.

[5] C. P. Iklima and M. Nasir, "Klasifikasi Jenis Pisang Menggunakan Metode K- Nearest Neighbor ( KNN )," vol. 1, no. 1, pp. 11-14, 2017.

[6] Johan Wahyudi and Ihdahubbi Maulida, "Pengenalan Pola Citra Kain Tradisional Menggunakan Glcm Dan Knn,” J. Teknol. Inf. Univ. Lambung Mangkurat, vol. 4, no. 2, pp. 43-48, 2019.

[7] D. Putra Pamungkas, K. KUNCI Anggrek, and O. Korespondensi, "Ekstraksi Citra menggunakan Metode GLCM dan KNN untuk Indentifikasi Jenis Anggrek (Orchidaceae)," Innov. Res. Informatics, vol. 1, no. 2, pp. 51-56, 2019.

[8] L. Sebastian Rori, "IMPLEMENTASI K-NEAREST NEIGHBOR UNTUK MENGENALI POLA CITRA DALAM MENDETEKSI PENYAKIT KULIT,” 2017. 
[9] M. A. Hasan, "Pengenalan Motif Songket Palembang Menggunakan Deteksi Tepi Canny, PCA dan KNN," vol. 6, no. 1, pp. 1-7, 2020.

[10] Z. A. A. Feri Agustina, "Identifikasi Citra Daging Ayam Kampung dan Broiler Menggunakan Metode GLCM dan Klasifikasi-NN," J. Infokam, vol. XVI, no. 1, pp. 25-36, 2020.

[11] C. Wijaya, "Klasifikasi Pneumonia Menggunakan Metode K- Nearest Neighbor Dengan Ekstraksi GLCM,” vol. 1, no. 1, pp. 33-44, 2020.

[12] F. S. Ni'mah, T. Sutojo, and D. R. I. M. Setiadi, “Identifikasi Tumbuhan Obat Herbal Berdasarkan Citra Daun Menggunakan Algoritma Gray Level Co-occurence Matrix dan K-Nearest Neighbor," J. Teknol. dan Sist. Komput., vol. 6, no. 2, pp. 51-56, 2018.

[13] E. K. Ratnasari, A. Wikaningrum, T. Informatika, F. Teknik, and U. Soetomo, "Pengenalan Jenis Buah pada Citra Menggunakan Pendekatan Klasifikasi Berdasarkan Fitur Warna Lab dan Tekstur CoOccurrence," vol. 1, no. 2, pp. 88-97, 2016.

[14] G. T. Situmorang, A. W. Widodo, and M. A. Rahman, "Penerapan Metode Gray Level Cooccurence Matrix ( GLCM ) untuk Ekstraksi Ciri pada Telapak Tangan,” J. Pengemb. Teknol. Inf. dan Ilmu Komput., vol. 3, no. 5, pp. 4710-4716, 2019.

[15] O. D. Nugraheni, "Klasifikasi Inti Sawit Berdasarkan Analisis Tekstur dan Morfologi Menggunakan K-Nearest Neighborhood (KNN)," J. Chem. Inf. Model., vol. 53, no. 9, pp. 1689-1699, 2019.

[16] F. Wibowo, D. K. Hakim, and S. Sugiyanto, "Pendugaan Kelas Mutu Buah Pepaya Berdasarkan Ciri Tekstur Glcm Menggunakan Algoritma K-Nearest Neighbors,” J. Nas. Pendidik. Tek. Inform., vol. 7, no. 1, p. 100, 2018. 